\title{
DOSSIÎE
}

Sociologias, Porto Alegre, ano 16, no 36, mai/ago 2014, p. 74-103

\section{El don: entre las prácticas intersticiales y el solidarismo}

ADRIÍN SERIBANO"

\section{Resumo}

El presente trabajo busca hacer evidente al solidarismo como la "pérdida del don", conforme expuesto por Mauss, en el contexto de la situación colonial, de los procesos de expansión capitalista en la actualidad. Como objeto de análisis y mediación hermenéutica, hemos seleccionado a la Responsabilidad Social Empresarial (RSE) como una forma del solidarismo cuyas prácticas llevan a un conjunto de situaciones que pueden describirse como pornográficas. Para lograr el objetivo explicitado, hemos seguido la siguiente estrategia argumentativa: a) se sintetizan algunas pocas coordenadas de carácter teóricos que permitan entender la centralidad del don y se explicita nuestra idea de solidarismo, b) se realiza un triple análisis: de la conceptualización de la RSE y de las experiencias de RSE de algunas corporaciones internacionales en Argentina; y c) se exponen nuestras ideas sobre prácticas intersticiales en tanto hiatos que quiebran a la economía política de la moral como una totalidad que demanda la "pérdida" de todo tipo de don.

Palabras clave: Responsabilidad Social Empresarial. Mauss. Solidarismo. Reciprocidad.

* Universidad de Buenos Aires. (Argentina) 
Sociologias, Porto Alegre, ano 16, no 36, mai/ago 2014, p. 74-103

\section{The Gift: between the interstitial practices and solidarism}

\section{Abstract}

This paper seeks to expose solidarism as the "loss of the gift", as discussed by Mauss, by analyzing it in the colonial context, within the processes of current capitalist expansion. Corporate Social Responsibility (CSR) is taken as object of analysis and hermeneutic mediation, as a form of solidarism whose practices lead to a set of situations that can be described as obscene. The argumentative strategy chosen to reach this proposed objective comprised: a) the synthesis of some theoretical guidelines that allow to understand the centrality of the gift and the description of our conception of solidarism; b) a triple analysis is performed on the conceptualization of CSR and on CSR experiences of some international corporations in Argentina; c) the explanation of our ideas on interstitial practices as gaps that break the moral economy while a totality that requires the "loss" of all kinds of gift.

Keywords: Corporate Social responsibility. Mauss. Solidarism. Reciprocity.

\section{Introducción}

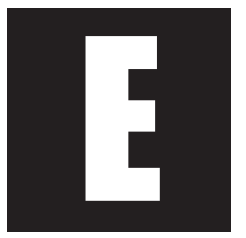

scribir en la actualidad un artículo tratando de lo expuesto por Mauss sobre el don es una empresa difícil no solo por la abrumadora cantidad de trabajos sobre la temática, no solo por la estructura y contenido del Ensayo sobre el Don... sino, y principalmente, por las consecuencias múltiples que acarrea analizar el fenómeno en nuestros días. Más aún, si se toma en consideración el señalamiento realizado por Mauss en la conclusión como un desafío analítico:

Estos hechos no sólo iluminan nuestra moral y no sólo nos ayudan a dirigir nuestro ideal, a partir de ellos podemos analizar mejor los hechos económicos más amplios, e incluso este análisis nos ayuda a percibir mejor los procesos de gestión aplicable nuestras sociedades. (Mauss, 2002, p.96) 
Inscripto en el campo que abrieran las conclusiones aludidas, el presente trabajo busca hacer evidente al solidarismo como la "pérdida del don" en el contexto de la situación colonial, en los procesos de expansión capitalista en la actualidad. Como objeto de análisis y mediación hermenéutica, hemos seleccionado a la Responsabilidad Social Empresarial (RSE) como una forma del solidarismo cuyas prácticas llevan a un conjunto de situaciones que pueden describirse como pornográficas. Es decir, tomamos a la RSE como una forma de paroxismo de las condiciones de subversión del don que hacen evidente la operatoria de "pérdida del don" que reside en la religión neo-colonial en tanto constitutiva de la economía política de la moral.

Para lograr el objetivo explicitado, hemos seguido la siguiente estrategia argumentativa: a) se sintetizan algunas pocas coordenadas de carácter teóricos que permitan entender la centralidad del don y se explicita nuestra idea de solidarismo, b) se realiza un triple análisis: de la conceptualización de la RSE y de las experiencias de RSE de algunas corporaciones internacionales en Argentina; y c) se exponen nuestras ideas sobre prácticas intersticiales en tanto hiatos que quiebran a la economía política de la moral como una totalidad que demanda la "pérdida" de todo tipo de don.

El perder es un "topos" del recuerdo y éste es el núcleo político de la memoria. La pérdida es parte constitutiva de la melancolía y ésta es el componente básico de la disipación de la autonomía. Sin memoria y sin autonomía la economía política de la moral opera la gestión de las políticas de los cuerpos y de las emociones. El solidarismo (en especial en su forma RSE) actúa en esa dirección. 


\section{El don y el solidarismo: algunas notas conceptuales}

En este apartado, se busca introducir conceptualmente algunos pocos rasgos sobre el don y hacer explícito nuestro concepto de solidarismo en tanto parte trinitaria de la religión neo-colonial.

\subsection{El contexto teórico: Mauss, el don y su herederos}

En sus estudios sobre el don, Mauss encontró una práctica social la cual podía usar como operador analítico, creyendo que, a partir de ella, las ciencias sociales podían formular bajo nuevas formas los viejos problemas. En dicho contexto sostiene:

$Y$, como constatamos que esta moral y economía siguen funcionando en nuestras sociedades de manera constante y, por así decirlo, de modo subyacente, y como creemos que hemos encontrado aquí uno de los pilares humanos en que se basan nuestras sociedades, podemos derivar algunas conclusiones sobre algunos de los problemas morales planteados por la crisis de nuestro derecho y la crisis de nuestra economía y nos detendremos allí (Mauss, 2002, p.8).

La propuesta de Mauss y de sus herederos es que es necesario ver en el don una práctica social la cual excede el intercambio y encuentra en el dar, recibir y retribuir una pista "universal" de la constitución del lazo social. Son muchos los trabajos publicados en América Latina (y en especial en Brasil) que pueden mencionarse como reconstrucciones e intentos de profundizaciones del legado de la teoría del don de Mauss. Un ejemplo de los trabajos aludidos es el de Sigaud (1999) As vicissitudes do Ensaio sobre o dom, donde se puede leer una "historia intelectual" de las recepciones, críticas y malentendidos sobre y desde el Ensayo sobre el Don.

Desde una perspectiva teórica y epistemológica, es necesario mencionar el trabajo de Paulo Henrique Martins (2005), que expone los cruces y 
articulaciones entre los legados teóricos/epistémicos y los contextos de producción y aplicación del don como paradigma para las Ciencias Sociales.

El trabajo de Herrero Pérez, Nieves (1985), Reflexiones en torno al concepto de 'Hombre Total' de Marcel Mauss, puede ser considerado como un ejemplo de la recepción de Mauss desde preocupaciones filosóficas. Otro texto que se puede referir es el de Sabourin quien aboga por realizar una relectura de la estructura de reciprocidad del siguiente modo:

Nesse embate da reciprocidade, tal valor ético é compartiIhado pelos protagonistas como um todo indiviso, invisivel, um terceiro incluído.Para evidenciar esse "terceiro" é possivel recorrer a uma estrutura que não seja um artifício, como imagina Mauss, mas uma estrutura de reciprocidade bem concreta, ternária em vez de binária: precisamente a estrutura de reciprocidade simétrica (Sabourin, 2008, p.134).

El legado de Mauss ( $y$, en especial, el referido al concepto de don) permanece aún en estado de controversia, discusión y diálogo - un ejemplo de ello es la proximidad/distancia entre don y reciprocidad que Abduca (2007) ha presentado en su trabajo La reciprocidad y el don no son la misma cosa, en el cual sostiene:

Ahora podemos ver que 'reciprocidad', 'don', 'intercambio', son formas, que pueden estar presentes en diferentes situaciones sociales, sean igualitarias, sean 'tributarias' o 'redistributivas'. Hay que distinguir, en definitiva, no sólo entre dones y 'reciprocidad', sino entre dones de bienes de consumo directo, (que podrían llamarse valores de uso simples) y bienes de uso que no son de consumo directo (valores de uso desdoblados). Los bienes de consumo directo tienden a circular en circuitos de dones de valor igual: circuitos cerrados. Los valores de uso desdoblados, tesaurizables, tenderían a circular en circuitos abiertos, y aumentando de valor (a diferencia de la moneda comercial) con el correr de la circulación (Abduca, 2007, p.120). 
Sin duda no es posible dejar de mencionar aquí el impacto y trascendencia del movimiento (y revista) M.A.U.S.S. (Movimiento Antiutilitarista en las Ciencias Sociales) cuya visibilidad entre nosotros se da en la figura de Alain Caillé; como así, tampoco a los esfuerzos y múltiples producciones realizadas en América Latina por Paulo Henrique Martins.

En el contexto de lo señalado es posible advertir que aparece, desde las ideas de Mauss, un conjunto de propuestas muy productivas y desafiantes que, parafraseando a Paul Ricoeur, "dan que pensar".

Assistemático, inimigo das respostas prontas e mastigadas, o paradigma da dádiva não é uma máquina de soprar soluções, mas de inspirar questões. Nesse sentido, é tudo menos paradigmático. Chega a ser, num certo sentido, e por excelência, antiparadigmático (Caillé, 1998, p.19).

Es basados en lo que expresara claramente Caillé sobre el don como paradigma, que nosotros aquí retomamos la "pérdida del don" como rasgo de las potencias mercantilizadoras de la expansión actual del capitalismo. Para expresarlo de otro modo, intentamos ilustrar aquí cómo, para encontrar la fuerza del don como práctica intersticial, debemos observar los ingentes esfuerzos de las relaciones capitalistas por "perderlo" en sus propias redes de resignificación. Perder el don significa extraviar una coordinación de la acción basada en la reciprocidad. En términos de prácticas sociales, dicha estrategia de extravío se da a través de y por el solidarismo. En dicho marco, en lo que sigue, se sintetizan los componentes conceptuales básicos.

\subsection{El solidarismo: una aproximación conceptual}

En la expansión global del capitalismo, se puede constatar la constitución trinitaria de una religión del desamparo, de una religión neo-colonial que opera como componente fundamental de la economía política de la moral vigente (Scribano, 2013). Para garantizar la operatividad de las aludidas 
prácticas ideológicas, la política (institucional) debe crear la nueva religión de los países neocoloniales dependientes, una que reemplace la - ya antigua trinidad de la "religión industrial"1 libertad y felicidad sin restricciones, por la trinidad de los expulsados, compuesta por el consumo mimético, el solidarismo y la resignación. Religión cuya liturgia es la construcción de las fantasías sociales, donde los sueños cumplen una función central en tanto reino de los cielos en la tierra, y la sociodicea de la frustración, el papel de narrar y hacer presentes-aceptables los fantasmáticos infiernos del pasado vuelto presente continuo.

El consumo mimético implica un conjunto de prácticas conectadas transversalmente que se elaboran en tanto se produce la absorción de propiedades de un objeto como acto de apropiación del mismo en forma de fantaseo de las cualidades del sujeto portador de dicha acción.

El solidarismo es una relación de sutura de las ausencias inscriptas en un sujeto llevada adelante por otro u otros sujetos, que deja indemne los procesos que causan dichas ausencias.

La resignación es una manera de hacer cuerpo a la desfuturización de las expectativas y deseos de un sujeto, construida como efecto de la aceptación de la totalidad cerrada de los límites impuestos por sus condiciones materiales de existencia.

Mandatos sociales se instalan como las "nuevas tablas" de la Ley. Consuma que será feliz... Sea bueno alguna vez en el día... iResígnese! Porque eso es lo único que $U d$. puede hacer... son algunos de esos mandatos. Desde - y para - esta trinidad mobesiana entre el consumo, que nos hace ser alguien; la solidaridad, que al único que beneficia es al que da; y la resignación que lo único que hace es procurar la aceptación de la limitación

${ }^{1}$ Nos aproximamos aquí, con varias diferencias, a Erich Fromm en su exposición de la idea de religión industrial. Cf. FROMM, E. Avere o essere? Milano: Modadori Editore, 1977. 
de la capacidad de acción, existen consecuencias sociales de multiplicación colectiva que se ritualizan y entrelazan. Es decir, ¿cuáles son las pastorales de esa religión del capitalismo dependiente? Son dos: la sinestesia social y la ataxia social. Desde la primera, las vivencialidades se inscriben en un mundo hipersensibilizado donde las sensaciones se superponen e indiferencian; desde la segunda - en tanto la imposibilidad de coordinar movimientos conjuntos - los sujetos aceptan el atomismo social.

Al Solidarismo lo constituye un conjunto de prácticas que operan como mecanismo de sutura de las diferencias y desigualdades entre clases. Dichas prácticas se caracterizan, entre otros rasgos, por: invertir el lugar de lo colectivo y lo individual, borrando sus diferencias; diluir los regímenes de cooperación social, reemplazados por ficciones culpabilizantes; dejar a los sujetos que reciben en situación iterativa de donatario; reemplazar la presencia estatal por la acción privada; y re-inaugurar la filantropía y la beneficencia privada como mecanismos de atención de carencias.

La solidaridad naturalizada como potencia del que más tiene deviene solidarismo como exceso que da lugar a la anulación de sus propios fundamentos. Lo que es un resultado de la estructuración social (en tanto colectivo) - la carencia - es in-vertido, como consecuencia de una práctica individual suturada por otra acción individual de quien da. El solidarismo necesita la aceptación de los sujetos de su estado de carencia y exige la ficcionalización de una culpa social sin responsables. Es en este contexto que la religión neo-colonial implica un proceso de redefinición de los contenidos y alcances de la filantropía como mecanismo social que, privatizando la desigualdad, "elimina" la necesidad de intervención estatal.

Tal como en una unidad trinitaria, los tres vértices de la religión aludida se entraman ocupando y torsionando en diversos sentidos sus lugares. Desde esta perspectiva, la lógica de la resignación es el punto de partida de la mimetización con el Otro que nos agrede y agrada desde el poder 
colonial. Tomando en cuenta otra banda de la compleja trama dialectizada, el consumo como marca identitária (aquello que nos hace ser alguien), se conecta con el solidarismo como iteratividad de la falta (al único que beneficia es al que da) y la resignación como coagulación de la acción.

Es en este contexto que explorar los caminos teóricos-empíricos que el solidarismo, en tanto práctica ideológica, toma en la actualidad es un ejercicio crítico indispensable. Como ya hemos anticipado, se ha seleccionado a la RSE como objeto analítico, tarea que reflejamos en el próximo apartado.

\section{El solidarismo como extravío/pérdida del don/reciprocidad en la religión neo-colonial}

Los estados dan, los gobiernos dan, las empresas dan, los individuos dan, las iglesias dan, las ONGs dan, el mundo contemporáneo parece estar superpoblado de acciones donde el dar las constituye. En el presente apartado, lo que buscamos son las huellas de las prácticas de RSE que nos permitan observar cómo y de qué modo ellas son parte fundamental de una operatoria para perder el don, disipándolo bajo la forma de solidarismo. Y, en el mismo proceso, aprender más sobre las múltiples facetas que en las prácticas cotidianas adquiere el aludido solidarismo. Para logar este cometido, en primer lugar, se exploran las definiciones de RSE; en segundo lugar, hemos elegido 6 corporaciones multinacionales que operan en Argentina y que poseen "programas de RSE" como ejemplos de las múltiples "caras" del solidarismo. Estas dos aproximaciones nos permitirán acceder a un conjunto de rasgos del solidarismo en su forma de RSE. 


\subsection{Responsabilidad Social Empresarial: una mirada introductoria}

Existen hoy múltiples, diversos y muy difundidos estudios sobre el contenido, alcance y prácticas asociadas a la RSE. Desde economistas, pasando por administradores públicos hasta llegar a trabajadores sociales procuran analizar, diseminar y también criticar el sentido y funciones de la RSE. Dado el objetivo de este trabajo, solo haremos referencia a algunos rasgos básicos de la RSE, para que sirvan de telón de fondo conceptual y horizonte de comprensión del análisis de las experiencias que aquí se realiza.

Recientemente se ha publicado la norma ISO 26000-2010 y es desde y sobre ella que en la actualidad se discute y actúa en los sectores y actores comprometidos con su aplicación. La aludida norma es un documento que pretende universalizar lo que respecta a este tema. De acuerdo a ella, la RSE es la responsabilidad de una organización ante los impactos que sus decisiones y actividades ocasionan en la sociedad y el medioambiente, a través de un comportamiento transparente y ético que: contribuya al desarrollo sostenible, incluyendo la salud y el bienestar de la sociedad; tome en consideración las expectativas de sus partes interesadas; cumpla con la legislación aplicable y sea coherente con la normativa internacional de comportamiento; y, además, esté integrada en toda la organización y se lleve a la práctica en sus relaciones².

Según lo informado por IRAM³ Argentina la ISO 26000 que expresa la RSE se basa en siete (7) principios: rendición de cuentas, transparencia, comportamiento ético, respeto a los intereses de las parte interesadas, respeto al principio de legalidad, respeto a la norma internacional de comportamiento y respeto a los derechos humanos.

\footnotetext{
${ }^{2}$ Para ver la definición dada por ISO Cf. http://www.iso.org/iso/iso26000_sr.pdf ${ }^{3}$ Instituto Argentino de Normalización y Certificación.
} 
Sin embargo, hay que aclarar, como hacen evidente Abreu y Badii (2006), la pluralidad de enfoques y énfasis respecto a la RSE tanto por parte de académicos como de las instituciones, dando como pauta de una "evolución" del concepto/práctica lo siguiente:

Fisher (2004) afirma que la evolución del concepto moderno de responsabilidad social empresarial ha sido descrita por Archie Carroll (1999). En los años 50, de acuerdo a Carroll, una literatura formal en el tema comenzó a desarrollarse. Durante los años 60 y 70, las definiciones de RSE se expandieron y proliferaron. El enfoque en investigación empírica y temas alternativos tales como el de desempeño en RSE y la teoría de los stakeholders marcaron los años 80. Este enfoque continuo en los 90 hasta el presente con el concepto de RSE suministrando las bases o punto de partida para conceptos y temas relacionados. Paralelamente a la investigación en el área de RSE, los investigadores del ámbito gerencial comenzaron a estudiar ética empresarial en los $60 \mathrm{y}$ al principio fue dicho que esto era simplemente otra moda gerencial, sin embargo, el interés en la ética empresarial ha aumentado desde ese entonces (Trevino; Nelson apud Abreu; Badii, 2006, p.55).

En el contexto de la pluralidad señalada, es posible advertir, tal como lo señalan Chirinos, Fernández y Sánchez, que la RSE es, ante todo, una práctica empresarial:

La responsabilidad social no es una moda, es una necesidad convertida en estrategia que permite desarrollar ventajas competitivas evidentes, por acción y comunicación, para los públicos organizacionales, generando beneficios tangibles y útiles para el desarrollo social, económico, cultural, entre otros (Chirinos; Fernández; Sánchez, 2012, p.1).

Posición que refuerza Azua (2007) en su artículo La responsabilidad social corporativa como refuerzo de la estrategia y la competitividad empresarial, título que exime de la necesidad de enfatizar las conexiones entre las prácticas de RSE y su lugar en los objetivos empresariales. 
En la misma dirección, Aguilera Castro y Puerto Becerra sostienen

La Responsabilidad Social Empresarial (RSE) ofrece una nueva alternativa de "competir", que está concebida como la transferencia de valor agregado a la sociedad; valor que se espera que en el mediano o largo plazo se convierta en fuente de ventaja competitiva, evidentemente, si así lo advierte oportunamente la organización (Aguilera Castro; Puerto Becerra, 2012, p. 3).

En este contexto, desde hace algunos años, se ha incluido al Estado como promotor de la RSE a través de las políticas públicas. Sobre dicho rol de promotor existen ya numerosos estudios y documentos oficiales. En uno de ellos, por ejemplo, se sostiene:

Así pues, se hace evidente que cuando se habla de RSE la intervención del Estado resulta decisiva, ya que debe aportar el entorno adecuado y la base apropiada para el desarrollo de empresas socialmente comprometidas. Asimismo, éste debe incentivar deliberadamente la RSE en ciertos campos específicos (Chumaceiro Hernández et al., 2013, p.310).

El Estado juega un rol fundamental para incorporar y expandir a la RSE como prácticas de sutura de las desigualdades y creación de la fantasía social que gira en torno al beneficio empresario como beneficio de todos.

Como es posible observar, las prácticas y principio de la RSE constituyen un conjunto de acciones y normas legales/morales que buscan mejorar la performance de ganancias corporativas a través de prácticas tendientes a asegurar las condiciones de consumo por parte de los clientes y de productividad en el caso de sus empleados.

El solidarismo encuentra en la RSE la expresión de un catecismo donde se entrecruzan los derechos humanos, el medio ambiente y el derecho positivo, puestos al servicio de la mantención del orden capitalista, revocando de toda potencialidad lo que habría de energía utópica en las prácticas del donar. La pérdida conceptual/normativa del dar-recibirretribuir es evidente. 
3.2 Experiencias de Responsabilidad Social Empresarial y solidarismo.

Como estamos procurando mostrar, la RSE es una práctica global. Las grandes multinacionales, las principales corporaciones, las empresas a escala planetaria han abrazado con fuerza el catecismo a que hicimos alusión arriba. Para mostrar cómo funcionan las prácticas de dichas empresas, hemos seleccionado seis (6) que tienen presencia en Argentina, en áreas productivas claves: alimentación, minería, banca, tecnología, petróleo e industria farmacéutica. Lo que sigue es un resumen del análisis de sus páginas web e informes sobre RSE con la intención de descubrir/ reforzar algunos rasgos del solidarismo como práctica ideológica.

Para comenzar, digamos que existen, en todas estas "experiencias", algunas constantes que, de una manera u otra, remitirían al conjunto de discusiones sobre el don ${ }^{4}$ que arriba sintetizamos, pero que a los fines de este artículo se reproducen como parte de la intención de señalar la "pérdida del don".

a) Es importante considerar un hilo conductor de todas estas prácticas: es su carácter de acción instrumental. Si bien se mezclan, revisten y enmascaran con acciones "dirigidas a los otros", el tipo de acción entablado es aquel dirigido por el cálculo medio- fines en el contexto de la producción capitalista.

b) Otra banda mobesiana que une/despliega las prácticas aludidas está en el hecho de que es la decisión del donante que las crea: se deben pedir, se deben "concursar", se deben merecer, se debe dar garantía de poder seguir solo, pero siempre es la voluntad del donador la mandante. Y es ésta voluntad del donante la que instaura el campo de intervención objetual de la práctica, creando así el circuito de obligaciones por él contraídas.

${ }^{4}$ Somos conscientes de en lo que las discusiones aludidas se ha explorado sobre cálculo, racionalidad, instrumentalidad, etc. 
c) Finalmente, estas acciones instrumentales que crean territorios de aplicación para la RSE, al ser específicas, se realizan teniendo en cuenta el sector productivo de la empresa, y se deben referir siempre a unas redes de RSE que las potencian. Redes que abogan todas por la difusión y expansión de esas prácticas/principios, constituyendo así una política de las sensibilidades a escala global.

Estos puntos en común nos hacen reflexionar sobre un aspecto central del solidarismo: son "principios de acción", porque son prácticas, y como parte de la economía política de la moral toman su fuerza de ser operadores del cómo las prácticas devienen en principios morales.

\subsubsection{NESTLE: CVC mistificación como operación del solidarismo}

Nestlé es la compañía № 32 en el ranking global de compañías de Forbes para el 2013. Según esa misma fuente, tiene 339.000 empleados y sus ventas llegaron a $\$ 100,64$ billones de dólares. Según la información suministrada por la misma empresa, el total de ventas del Grupo (millones de francos suizos) fue, para 2012, de 92.186, y el beneficio neto, de 10.611, en esa misma moneda.

Su programa de RSE se denomina Crear Valor Compartido (CVC) y consiste en introducir una serie de acciones en toda su cadena de valor, desde la producción de materias primas, pasando por la gestión de mano de obra y producción de bienes hasta la constitución social de su público. El concepto de CVC se basa en una consigna pragmática: mejor empresa, mejor sociedad.

Creemos que podemos realizar una importante contribución a la sociedad si vamos más allá de la responsabilidad social de la empresa y creamos valor mediante nuestro negocio, tanto para nuestros accionistas como para el conjunto de la sociedad. Nuestra prioridad es crear valor compartido en nutrición, agua y desarrollo rural, y esto requiere una 
visión a largo plazo... Peter Brabeck-Letmathe, Presidente (Nestle, 2012, p.1).

La Creación de Valor Compartido se basa en compromisos fundamentales con la sociedad: observar los criterios más exigentes en el cumplimiento de las leyes, los códigos de conducta y los Principios Corporativos Empresariales de Nestlé y, al mismo tiempo, proteger el medio ambiente para las generaciones futuras Paul Bulcke, Consejero Delegado (Nestle, 2012, p.1).

El solidarismo como mistificación implica un conjunto de prácticas de fetichización del sentido de dar-recibir en que el donante establece su acción como constitutiva de la importancia de la misma. En la mistificación, la consecuencia del hacer torna intercambiables los lugares de donador-donatario de modo tal que mi interés utilitario-egocentrado se identifica con el interés del otro y de lo colectivo.

Crear valor es "compartir" la estructura del fetiche en que el "cuidado" de las dimensiones sociales de las prácticas de rentabilidad (nutrición, agua y desarrollo rural) adquiere la fisonomía de principio moral.

El dar como fetiche mezcla, sobreimprime, la cosa y el acto, cosifica la acción de recibir en términos de identidades y beneficios que adquieren, agregan y reproducen valor. El tinte religioso de la RSE pretende hacernos dejar este mundo, migrando a otro donde el que te quita te da, donde el que da tiene necesidad de un donatario para instanciar su voluntad de dar, donde el único que recibe es el que da. Aparece así, un paraíso donde se eliminan, mistificados, los "daños colaterales", las colonizaciones del futuro bajo la forma de mitigación de sufrimientos actuales y la naturalización de la insuficiencia del paradigma restitutivo. 
3.2.2 BARRICK GOLD: La carta de responsabilidad social empresarial la fantasía del solidarismo

Barrick Gold es la compañía no 659 en el ranking global de compañías de Forbes para el 2013 según esa misma fuente tiene 25.000 empleados y sus ventas llegaron a \$11.55 billones de dólares.

Como empresa mundial dedicada a la depredación de los bienes comunes bajo la cobertura de las modalidades extracción, la Barrick Gold enarbola su Carta de Responsabilidad Social como compromiso con la sustentabilidad y las comunidades locales,

Nuestro enfoque de sustentabilidad se basa en nuestros valores corporativos y en la Carta de Responsabilidad Social, que orientan nuestro compromiso con una conducta responsable hacia nuestros colaboradores, el ambiente, las comunidades y toda nuestra esfera de influencia. Nuestra Carta de Responsabilidad Social Empresaria confirma la visión de desarrollar todas nuestras actividades de exploración y explotación con integridad y excelencia, y establece cuatro ejes sobre los que debemos focalizarnos: Medio ambiente, Salud y Seguridad; Empleados; Comunidad y Ética (Barrick Argentina, 2012, p.2).

Nuestro trabajo de inversión social se centra en un enfoque a largo plazo, que permita el progreso de la comunidad, a través de programas con foco en el desarrollo comunitario, el fortalecimiento de la educación y las economías locales." .."Colaboración estrecha con la comunidad... Beneficios mutuos para la compañía y la comunidad..Un legado sustentable positivo (Barrick Argentina, 2012, p.6).

Como la RSE es una estrategia empresarial, nadie espera otra cosa del acto de dar que no sea que el mismo beneficie al que da. No se produce, así, expectativa ninguna sobre la incertidumbre que encierran las prácticas del don. 
Los cinco aspectos que la empresa reporta en su informe de RSE, desarrollo económico, educación, salud, energía-agua y arte-cultura-deporte elaboran una imagen del mundo donde la contaminación, el despojo de los activos ambientales, las consecuencias de la actividad a largo plazo quedan suprimidas por acción focalizadas e insuficientes en el marco de la constitución de la actividad minera como parte de la fantasía del desarrollo.

El solidarismo como fantasía refiere al conjunto de prácticas que plantea la inclusión de quien recibe en un estado de cosas que no le son posibles de vivenciar in acto. Empoderamiento, equidad, progreso suelen ser los vectores por donde se suelen delimitar la tierra prometida a siempre y cuando quienes reciben queden en condiciones de transito permanente hacia esos estados fantásticos del donante.

\subsubsection{ICBC: Asociativismo empresario- el solidarismo como oportunidad para el que da}

ICBC es la compañía no 1 en el ranking global de compañías de Forbes para el 2013. Según esa misma fuente, tiene 408,859 empleados y sus ventas llegaron a $\$ 134.77$ billones de dólares.

El ICBC, en Argentina, apoya sus prácticas de RSE en su Fundación, que además se enfoca en la formación profesional para el comercio internacional y en el fomento del "emprendedurismo".

Desde el área de Responsabilidad Social Corporativa, ICBC Argentina y su Fundación buscan crear valor social a largo plazo, invirtiendo recursos económicos y humanos -entendidos como capacidades personales-, en el apoyo a programas e iniciativas que tiendan al desarrollo sustentable de las comunidades en riesgo o de bajos recursos del país ${ }^{5}$ (ICBC, 2012, p.1).

\footnotetext{
${ }^{5}$ Ver en: <http://www.icbc.com.ar/institucional/institucional2.do? codTmst $=1 \& \mathrm{~N} 2=03 \% 20$ Responsabilidad\%20Social\%20Empresaria >.
} 
Sociologias, Porto Alegre, ano 16, no 36, mai/ago 2014, p. 74-103

Fundación ICBC canaliza la responsabilidad social empresaria de ICBC, promoviendo emprendimientos asociativos con otras fundaciones empresarias, organizaciones del tercer sector y entidades de bien público. Hoy los desafíos en el campo social son mayores y requieren renovar el compromiso asumido y buscar acciones creativas que aporten soluciones concretas para aquellos sectores que las necesitan. La elección de la metodología asociativa para llevar adelante los programas responde a dos ventajas fundamentales: multiplica los resultados obtenidos y propicia un mayor involucramiento de la empresa en particular y de cada uno de los actores en general, en cuanto a la evolución, desarrollo e impacto de cada uno de los proyectos ${ }^{6}$ (ICBC, 2012, p. 1).

Las prácticas de RSE se performan entre "algunos" para los "muchos" y están incorporadas al "trabajo de cara" de unos donantes que hacen de ello una oportunidad para pertenecer a los "pocos" que conforman ese "algunos". Es una oportunidad para el donante de hacer saber que da sin ninguna lógica de retribución, salvo la de aumentar su "presencia" entre los que pueden dar y así incrementar su imagen de poderoso.

Hay que dar junto con otros iguales al que da, con donantes: consolidando la posición de poder que implica la posibilidad de actuar construyendo escenarios "manejados" por unos pocos y articulando el me tienes que comprar lo que vendo con el además te ayudo para que me compres. Así, se deja en claro que el Estado no puede garantizar las condiciones de posibilidad de compra pues no garantiza la oportunidad de venta de esos cuerpos consumidores devenidos ahora en asistidos. Lo que son cada una de esas empresas para la venta lo reproducen en la ayuda: oligopolios del dar. Se extravía lo que hay en el don de práctica colectiva desfondando la potencial asociatividad. Una mueca cínica del hacer juntos.

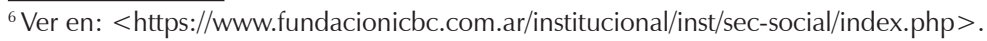




\subsubsection{IBM: El otro como yo, el solidarismo como espejo}

IBM es la compañía no 34 en el ranking global de compañías de Forbes para el 2013. Según esa misma fuente, tiene 466,995 empleados y sus ventas llegaron a $\$ 104.51$ billones de dólares.

IBM tiene un programa de Ciudadanía Corporativa que incluye acciones de RSE bajo la cobertura de uno de los enfoques posibles para dotar de "sentido" sus prácticas de relación con el público interno y externo.

Desde sus inicios, la misión de IBM está relacionada con acercar innovación y generar un mayor conocimiento que permita abordar los desafíos que plantea el mundo, tanto a nivel competitivo como desde un punto de vista de compromiso para con el entorno. En la Argentina nuestro equipo está avanzando en la construcción de un mundo más inteligente. Este compromiso se materializa en tres ejes estratégicos; ellos son: el cuidado del medioambiente, la educación y la calidad. Nuestra visión de sustentabilidad trasciende los límites de la organización y se infunde también en nuestra cadena de valor y en nuestro propio ecosistema. Es así como en IBM definimos una estrategia de Ciudadanía Corporativa que representa la gestión ética y transparente de nuestra empresa con todos los públicos con los que se relaciona, y el establecimiento de metas empresariales compatibles con el desarrollo sustentable. A su vez, esta política de Ciudadanía Corporativa está integrada a la estrategia del negocio. Por ser la educación y la formación de Recursos Humanos factores clave para el éxito de nuestra industria, nuestros esfuerzos van orientados en dicha dirección (IBM Argentina, 2011, p.1).

El solidarismo como prácticas que configuran un régimen especular del donante involucra la primacía de la mirada/reflejo de quien da. En dicha acción, constituye al que no tiene y modula la acción de recibir. Yo donante estimo que hay que hacer un mundo más inteligente y te voy a ayudar a serlo. 
Al darle al otro la "oportunidad" de ser como el que da, al ponerse el donante como espejo, al borrar las posibilidades equivalenciales con el que da, moldeando el deseo sobre el "para qué" se pierde en el don lo que hay en él de retribución posible. No hay imprevisibilidad ni estatuto paradójico del dar hay pura adecuación al Otro que da.

\subsubsection{CHEVRON: La inversión del invertir el solidarismo como ganancia}

Chevron es la compañía no 13 en el ranking global de compañías de Forbes para el 2013.Según esa misma fuente, tiene 62,000 empleados y sus ventas llegaron a $\$ 222.58$ billones de dólares.

Hay que dar para seguir ganando, hay que obtener rentabilidad en el mismo acto de dar.

La fructífera relación de Chevron con la industria energética latinoamericana comienza en los años 20, cuando iniciamos nuestras actividades de exploración y producción en la región. Hoy en día, no podemos sentirnos más orgullosos de las sólidas alianzas y del portafolio de negocios que hemos construido durante más de 90 años. Sin embargo, reconocemos que los retos y las expectativas de las comunidades también han evolucionado. El manejo del riesgo para ejecutar las actividades del negocio con excelencia, mientras se promueve la estabilidad y vitalidad de las comunidades donde operamos, es crucial para cubrir estas expectativas. Como creemos firmemente que el éxito de nuestro negocio está ligado al éxito de las comunidades, invertimos más de seis millones de dólares en proyectos para el desarrollo de la salud, educación y economía en la región latinoamericana en 2012. Nuestra prioridad número uno es producir energía rentable y confiable para apoyar el desarrollo económico y sustentable. Por esta razón, trabajamos de la mano con los gobiernos y organizaciones locales en la identificación de necesidades y en la determinación del alcance y enfoque de la inversión, asegurándonos así de que el valor que agregamos no solo sea permanente, sino además, medible (Chevron, 2012, p.1). 
La inversión del invertir es una propiedad de la razón hipostasiada y de la racionalización enmascarada en que el dar es la máscara de la mercantilización. El dar no desata nudos de obligaciones, despoja al otro de la capacidad de retribuir, cambia el flujo del dar-recibir-retribuir obturando el "regreso" del dar, extraviando el don.

El solidarismo como inversión "pone patas para arriba" a la misma noción de inversión, jugando en el hiato donde se despliega su sentido como ganancia futura y como cambio de posiciones en un estado de cosas. Lo propio como ajeno, lo que se debe con lo que se puede, la inversión del donante es colonización del futuro a través de crear las condiciones de posibilidad de sus ganancias.

Ganar en la RSE es subvertir el "orden del don", el juego se transforma deporte, la justa por la potencia deviene puro cálculo de poder, el deseo se trastoca en goce, el solidarismo es otra manifestación de Kant más Sade. El don se pierde quedando a la deriva en los laberintos cortados al talle del poder/goce.

3.2.6 BAYER: UNES Utilicemos Nuestro Espíritu Solidario - el solidarismo como práctica utilitaria

Bayer es la compañía no 120 en el ranking global de compañías de Forbes para el 2013. Según esa misma fuente, tiene 110,500 empleados y sus ventas llegaron a $\$ 52.45$ billones de dólares.

Bayer tiene como estrategia de RSE lo que denomina Bayer Emprender siendo uno de sus componentes un programa de voluntariado corporativo UNES.

Bayer Emprende es la denominación que unifica todas las acciones de Responsabilidad Social Empresaria (RSE) de Bayer en la región Cono Sur. Representa, mediante las campañas que engloba, un programa integral de RSE que responde a los valores de Bayer y tiene participación en ám- 
bitos como la educación, la salud, el cambio climático y el voluntariado corporativo, entre otros. Bayer Emprende actúa como nombre paraguas, que debe acompañar a las diversas campañas e iniciativas regionales. Además, constituye un esquema que permite sumar iniciativas futuras de las diferentes divisiones, unidades de negocios o países, sin que pierda entidad el programa integral de RSE de la Compañía (Bayer, 2012, p.1).

UNES, Utilicemos Nuestro Espíritu Solidario, es el nuevo nombre que unifica las diferentes iniciativas del proyecto solidario y voluntariado corporativo de Bayer en la región Cono Sur. Busca transmitir la cultura socialmente responsable de la compañía, y a su vez, generar entusiasmo, compromiso y la participación activa de los colaboradores y la comunidad en general. UNES se aboca a necesidades de primer grado y se enmarca dentro de Bayer Emprende, el programa integral de Responsabilidad Social Empresaria en Cono Sur, que cuenta también con programas sociales en el área de Salud, Educación y Cambio Climático ${ }^{8}$ (Bayer, 2012, p.1).

El solidarismo como práctica útil es la forma maás pornográfica de lo que aquí hemos denominado "pérdida del don": si soy solidario que sea útil. Más allá de las múltiples discusiones teóricas que implicaría esta faceta del utilitarismo, es clara la equivalencia entre solidaridad=utilidad que profundiza el carácter de acción instrumental de la práctica del dar, más allá de las posibles paradojas de una acción de ese tipo.

Lo útil, lo usable, el dar como una variable del manejo de escenarios, como tiempo-espacio para mostrar que es "conveniente" dar. Conviene a la empresa, al trabajador en su carrera, que tiene que mostrar compromiso realizando valor para la empresa en y a través de dar sus

\footnotetext{
${ }^{7}$ Ver en: < http://www.bayer.com.ar/responsabilidad/iniciativas_concretas.php>.

${ }^{8}$ Ver en: <http://www.bayer.com.ar/responsabilidad/iniciativas_concretas.php\#4>.
} 
horas como voluntario. Sirve es utilizado por otros, por el público, por el entorno, sirve genera imagen, consolida oportunidades de negocio. Lo que hay de ritual en el don deviene "como si", se pierde lo que en él hay de inutilidad y disipación.

Las prácticas de ganar, de mistificar, de invertir, de espejo, de cinismo asociativo y fantasía conjuran al don sus hiatos intersticiales produciéndolo como componente de unas políticas de las emociones para una sujeción indeterminada del sujeto.

Como hemos analizado, la mistificación, la creación de fantasía, la oportunidad para el que da, el efecto del espejo, la inversión del invertir y la práctica utilitaria son rasgos básicos del solidarismo.

Mistificar es llevar al don por los caminos que recorren la indiferenciación como estrategia para disimular lo que hay de mercantilización en el solidarismo. Se crean así, territorios fantasiosos donde la pérdida de posición aludida oculta la persistencia de los mecanismos de desigualdad como meta. Se instancian por esta vía las prácticas del dar como ocasión para el donante en tanto presentación social en el mercado del dar. Consolidándose lo que hay de colonización en el solidarismo como estructura especular que procura hacer al otro a imagen y semejanza del donante. Se invierte en producir una inversión: que la ganancia sea registrada como un despojarse des-interesado; logrando que la utilidad transversalice y penetre toda acción de dar.

Como hemos visto, la importancia mundial del solidarismo como uno de los componentes básicos de la trinidad de la religión neo-colonial es más que evidente. Se ha evidenciado, al menos sintéticamente, el solidarismo como una pieza clave de la economía política de la moral en la actualidad.

El solidarismo constituye una práctica de desvío, de extravío y de pérdida de las potenciales fuerzas del don para reconstruir prácticas in- 
tersticiales, prácticas donde el dar-recibir-dar desvinculen a los objetos y las prácticas de un afán meramente instrumental desdiciendo a la verdad de la economía política de la moral como totalidad cerrada e inevitable.

Extraviar el don, para mercantilizarlo, implica operar sobre los dispositivos de regulación de las sensaciones para que ellos habiliten el solidarismo como único horizonte del dar. La pérdida del don involucra la ruptura de la dialéctica del dar-recibir-retribuir coagulando la acción en el dar. Extraviar el don significa ahogar lo que hay en él de potencia para el gasto festivo. La RSE constituye un conjunto de prácticas que, en la búsqueda de la rentabilidad, instalan al solidarismo como olvido de los caminos hacia el don. RSE conjuga una serie de acciones a través de las cuales el duelo por la pérdida de la oportunidad de vivir la potencia del don se sutura con el reingreso del gobierno del mundo de las cosas. Fetiche y mercancía revestidos de solidarismo se instalan nuevamente como los ejes de la economía política de la moral.

Ahora bien, tanto las prácticas "individuales" de solidarismo como las de RSE son parte de la religión neo-colonial. Religión que, por definición, es una totalidad rasgada y que, en sus intentos de presentarse como aquello que no posee una unidad externa que la niegue, de presentarse como un todo sin exterioridad alguna, deja entrever y no puede obturar: los pliegues, quiebres y faltas instanciados en un conjunto de prácticas que le son intersticiales.

\section{A modo de cierre: prácticas intersticiales}

La religión neo-colonial implica, en su propia vocación de afirmación, hiatos, quiebres y pliegues, que, al disponerse como intersticios, desmiente el régimen de verdad de una economía política de la moral vigente globalmente. Ante el consumo mimético, la resignación y el so- 
lidarismo, se efectivizan, día a día, prácticas que concretan la aludida desmentida. Son las prácticas, muchas veces, silenciadas y prohibidas: la felicidad, el amor y la reciprocidad. En lo que sigue, reproduciremos lo que hace tiempo ya venimos proponiendo como ejes helicoidales para analizar y reconstruir las aludidas prácticas intersticiales ocupándonos especialmente de la reciprocidad.

Elegir ser feliz es siempre una disposicionalidad de combate contra el dictum mercantil que impone al consumo mimético como única vía hacia la felicidad. Elegir amar es un acto destituyente de la condena coagulante de vivir en la resignación. Elegir ser recíproco con (y ante) los otros es una práctica diluyente del solidarismo fetichista. En América Latina miles y millones de sujetos, expropiados, condenados y expulsados aparecen como el musgo entre la piedra afirmando su capacidad de decidir.

La práctica social que denominamos felicidad se refiere a estados afectivos-cognitivos complejos en que se concretan para el ser humano la liberad para el desarrollo individual y la capacidad para experimentar gratificaciones sensoriales. Como hemos desarrollado en otro lugar una de las prácticas sociales más ligadas a la felicidad es el gasto festivo (Scribano, 2009d). La felicidad es la vivencia de la propia potencia de sentirse autónomo para obrar, que la destitución y desregulación del gasto festivo potencian como acontecimiento. Las prácticas de felicidad que anidan en el gasto festivo, liberando la creatividad, la expresividad y la destrucción de la mercantilización de la vida, rompen el capricho repetitivo del placer instantáneo donde siempre regresa lo viejo en lo nuevo del consumo para ser consumido.

La felicidad es del orden del estar para el fruto que re-nace en su donación; se efectiviza en el registro del dar(se) en reciprocidad y de la esperanza del amar(se), donde el todo vive en la parte y donde la parte muestra al todo. 
Las Prácticas-del-querer los hiatos de la resignación (Scribano, 2009c) e involucran lo que denominamos amor filial, conyugal y cívico. Aquí nos permitimos pensar este conjunto de problemáticas desde la necesidad conceptual que implica tematizar a la esperanza como contracara de la resignación. La esperanza tiene dos características básicas: a) se hace visible en la presentificación del tiempo-espacio, es decir, en la instanciación que se produce como práctica social que vivencia el pasado-presentefuturo en tanto hoy-ahora y; b) se manifiesta como una gesto anticipatorio de prácticas que aún no son pero están siendo. Comprendemos como condición de posibilidad de la esperanza, bajo el entendido de que el futuro es ahora, a un juego dialéctico entre amor filial, amor conyugal y amor cívico. Dicha "condición de posibilidad" debe ser concebida en el contexto de lo desarrollado por Marx (y otras tradiciones) respecto a las sensibilidades y el disfrute. Estas "prácticas-del-querer" son el resultado de sociabilidades hechas carnes y huesos que permiten, al menos potencialmente, reconectar las relaciones yo-tu-otro que el desarrollo de las prácticas capitalistas coagula en la mercantilización.

La reciprocidad como base de un disfrute otro (Scribano, 2009b) involucra el quiebre del solidarismo. La reciprocidad en tanto práctica intersticial involucra tres momentos del intercambio intersubjetivo en que se destituye, al menos parcialmente, el rasgo primario del consumo mimético consistente en transformar al consumidor en objeto. Los tres momentos no tienen un orden cronológico pensando al intercambio como actividad, ni tampoco una jerarquía de sentido - los mismos pertenecen a un mismo proceso helicoidal que puede recorrer su propia figura en fases ascendentes y descendentes. Es decir, la reciprocidad no es normativa sino una experiencia abierta y multi-cromática. Uno de esos momentos gira en torno al dar-recibir-dar, otro alrededor de los juegos de heteroreconocimiento y el tercero está ligado al compartir. 
La gramática de la "acción-en-reciprocidad" se abre y contrae alrededor de un nosotros como sujeto de la acción, donde la especulación mercantil es puesta entre paréntesis emergiendo el dar(se) en la donación equivalente.

La malla de conocer, conocerse, re-conocerse y ser reconocido de (y en) la reciprocidad destituye la dependencia de un Otro (fantasmal y fantasioso) que genera autonomía en el hetero-reconocimiento. La reciprocidad es una práctica intersubjetiva que configura el compartir como lógica de interacción en un doble sentido: lo común desautoriza la posesión individual compulsiva y distribuye las partes de la vida en el mundo con otros en condiciones de equivalencias.

Estos tres momentos adquieren facetas heterogéneas y múltiples, pero siempre se refieren al resultado del intercambio como una identidad. Identidad en la gramática de la acción donde ésta se expresa de la misma manera entre los sujetos que participan en ella. Identidad de la predicación de los atributos que relacionan a los participantes de un intercambio. Identidad que significa un mismo flujo de energía puesto en juego en el intercambio.

Desde esta perspectiva podemos visualizar una banda mobesiana dividida en tres que coloca una y otra vez al dar-recibir-dar en diferentes planos de apertura y reproducción. En los planos de dichas bandas, el juego de reconocimiento y hetero-reconocimiento aparece como un horizonte de una identidad compartida.

Es en este sentido que una práctica de reciprocidad destituye el consumo mimético en su cara más oculta pero también más obscena: transformar al individuo consumidor en objeto.

Las diversas formas de asociaciones y asociacionismos que se evidencian en América Latina no están exentas de las "contradicciones" propias del sistema de "mercado", donde la tríada mercancía, dinero y consumo 
implica (in)ciertas relaciones de clases. Pero un análisis que rescate el más acá de dichas contradicciones abre las bandas de su disposición mobesiana. Las prácticas a las que nos referimos implican una celebración de la reciprocidad en tanto momento de ruptura con el consumo mimético, negando convertir en centro de los intercambios a un sujeto devenido cosa consumible. Señalar en dirección de las prácticas intersticiales implica asumir la necesidad de elaborar teorías sociales del sur, cuya intención crítica involucre descolonizar lo que hay en la RSE en particular y en el solidarismo en general de prácticas ideológicas al servicio de la expansión global del capital.

Adrián Scribano - Investigador Principal de Consejo Nacional de Investigaciones Científicas y Técnicas, Universidad de Buenos Aires. Director del Centro de Investigaciones y Estudios Sociológicos (Argentina). $\gg$ adrianscribano@gmail.com

\section{Referencias}

1. ABDUCA, R. G. La reciprocidad y el don no son la misma cosa. Cuadernos de Antropología Social, Buenos Aires, n. 26, p. 107-124, 2007.

2. ABREU, J. L.; BADII, M. Análisis del concepto de responsabilidad social empresarial, Daena: International Journal of Good Conscience, v. 2, n.1, p. 54-70, Oct. 2006 - Marzo 2007.

3. AGUILERA CASTRO, A. et al. Crecimiento empresarial basado en la Responsabilidad Social. Pensamiento \& Gestión, Barranquilla, n. 32, p. 1-26, enero-junio, 2012.

4. AZUA, S. La responsabilidad social, corporativa como refuerzo de la estrategia y la competitividad empresarial. Revista Escuela de Administración de Negocios, Bogotá, n. 61, p. 73-75, septiembre-diciembre 2007.

5. BARRICK ARGENTINA. Reporte de Sustentabilidad. Resumen Ejecutivo, 2012.

6. CAILLE, A. O princípio de razão, o utilitarismo e o antiutilitarismo. Sociedade e Estado, Brasília, v.16, n.1-2, p. 26-56, 2001.

7. CAILLÉ, A. Nem holismo nem individualismo metodológicos. Marcel Mauss e o paradigma da dádiva. Revista Brasileira de Ciências Sociais, São Paulo, v. 13 n.38, p. 5-38, 1998. 
8. CHIRINOS, M.; FERNÁNDEZ, L.; SÁNCHEZ, G. Responsabilidad empresarial o empresas socialmente responsables. Razón y Palabra: Instituto Tecnológico y de Estudios Superiores de Monterrey, México - DF, n. 81, noviembre-enero 2012.

9. CHUMACEIRO HERNÁNDEZ, A. et al. Responsabilidad social empresarial y políticas públicas. Revista de Ciencias Sociales, Maracaibo, v. XIX, n. 2, p. 309321, abril-junio, 2013.

10. DE LA CRUZ, M. R. Responsabilidad social empresarial: diagnóstico de la situación actual en república Dominicana. Ciencia y Sociedad, Santo Domingo, v. XXXVII, n. 1, p. 64-76, enero-marzo, 2012.

11. HERRERO PÉREZ, N. Reflexiones en torno al concepto de "Hombre Total" de Marcel Mauss. Ágora: Papeles de Filosofía, Santiago de Compostela, v. 5, p. 49-58, 1985.

12. IBM ARGENTINA. Memoria de Ciudadanía Corporativa, 2009-2010.

13. IRAM. ISO 26000 - Responsabilidad social, 2011.

14. MARTÍNEZ LEÓN, I.; ARCAS LARIO, N.; GARCÍA HERNÁNDEZ, M. La influencia del género sobre la responsabilidad social empresarial en las entidades de economía social. REVESCO: Revista de Estudios Cooperativos, Madrid, n. 105, p. 143-172, 2011.

15. MARTINS, P. De Lévi-Strauss a M.A.U.S.S. - Movimento antiutilitarista nas ciências sociais: itinerários do dom. Revista Brasileira de Ciências Sociais, São Paulo, v. 23, n. 66, p. 105-130, fev. 2008.

16. MARTINS, P. A sociologia de Marcel Mauss: dom, simbolismo e associação. Revista Crítica de Ciências Sociais, Coimbra, n.73, p. 45-66, dez. 2005.

17. MAUSS, M. Essai sur le don. Forme et raison de l'échange dans les sociétés primitives. Année Sociologique, [S.I.], seconde série, 1923-1924. (Edition électronique, février 2002.)

18. SABOURIN, E. Marcel Mauss: da dádiva à questão da reciprocidade. Revista brasileira de Ciências Sociais, São Paulo,v.23, n.66, p. 131-138, fev. 2008.

19. SCRIBANO, A. La religión neo-colonial como la forma actual de la economía política de la moral. Rev. Prácticas y Discursos, Corrientes, ano 1, n.2, p. 1-20, 2013.

20. SCRIBANO, A. ¿Por qué una mirada sociológica de los cuerpos y las emociones? A Modo de Epílogo. In: SCRIBANO, A.; FIGARI, C. Cuerpo(s), Subjetividad(es) y Conflicto(s) Hacia una sociología de los cuerpos y las emociones desde Latinoamérica. Buenos Aires: CLACSO-CICCUS, 2009a. p. 141-151. 
21. SCRIBANO, A. 2009b Reciprocidad, Emociones y Prácticas Intersticiales In: MARTINS, P.; MEDEIROS, R. América Latina e Brasil em Perspectiva. Recife: Editora Universitária UFPE, 2009b. p. 189-204.

22. SCRIBANO, A. Las Prácticas del Querer: el amor como plataforma de la esperanza colectiva. In: LUHRS M. C.; GILABERT JUÁREZ, C.; CORTÉS GUARDADO, M. Amor y Poder. Replanteamientos esenciales de la época actual. Guadalajara: En prensa, 2009c.

23. SCRIBANO, A. Sociología de la felicidad: el gasto festivo como práctica intersticial en Yuyaykusun. Departamento Académico de Humanidades de la Universidad Ricardo Palma, Lima, n. 2, p. 173-189, 2009d.

24. SIGAUD, L. As vicissitudes do Ensaio sobre o dom. Mana - Estudos de Antropologia Social, Rio de Janeiro, v. 5, n.2, p. 89-124, 1999.

Recebido em: 17/02/2014

Aceite final: 30/05/2014 